\title{
Investigation on the Use of Pleko Ceiling Board for Heat Insulator and Sound Proofing Material Applications
}

\author{
Tomas U. Ganiron Jr \\ International Association of Engineers (IAENG), Hongkong \\ College of Architecture, Qassim University, Buraidah City \\ tomas@qec.edu.sa
}

\begin{abstract}
In this study, sound and thermal insulation properties of pleko ceiling boards were evaluated. A set of ceiling boards combined of 6 layers containing the foam plastic insulation board; pleko adhesives, mechanical fasteners, reinforcing fabric, plekote base coat and pleko finish were made. These components are being attached on the interior face including the existing projects of Exterior Insulation Finish Systems (EISF) are made to provide sound insulation comparison. The study showed that the thermal insulating properties of pleko board in ceilings maintain the protection of constructional elements against thermal impact and moisture related damage. Moreover, the acoustical properties of gypsum board and Styrofoam which is the main material in pleko board would serve as sound reflector of the reverberation of sound inside the room
\end{abstract}

Keywords: Ceiling board, ceiling insulation, construction materials, sound insulation, thermal insulation

\section{Introduction}

The ceiling industry calls for a more in novative and comprehensive materials in line with the fast developing trends of building construction. The thought of all these creative ideas comes up to the brilliant minds of young civil engineers to achieve intense study that would possibly change the history.

In ancient Egyptian temples the underside of the flat stone roof was generally painted blue with yellow stars, bands of hieroglyphics, and emblems of the heavens [1]. In Greek temples the pitched timber roof was sometimes left uncovered and sometimes hidden by a coffered (deeply paneled) ceiling, often decoratively painted. Roman ceilings were similar but also included flat ceilings of planks and plaster, as well as vaulted and dome ceilings of brick, concrete, or stone, such as the coffered dome of the Pantheism in Rome.

In the middle ages, churches and important secular buildings usually had pitched roofs, left open to show the structural timbers or later, covered by barrel, groined, or rib vaulting in the stone. Some ceilings were painted in all-over patterns or with biblical scenes. In the renaissance, most roof structures were hidden behind flat or domed ceilings, which might be richly ornamented. Some had carved and gilded coffering or molding, often framing paintings by great masters such as Titians and Veronese, as in the doge's Palace in Venice. Others had elaborate carved or molded plaster decoration sometimes extending into pendants, as in $16^{\text {th }}$ and $17^{\text {th }}$ century English country houses [2]. 
Ceilings in the 18th century were sometimes coved or curved into the walls where a right angle ordinarily would be [3]. Painting and decorative plasterwork was generally more delicate in Rococo or Neo-Classical buildings. Ceilings in 19th century, ceilings of plaster or acoustic tile, tend to be flat and unadorned. Frequently they hide elaborate heating, plumbing, air conditioning, and electrical systems. In many public buildings, however architects have chosen to reveal both the structural members and mechanical equipment, making them part of the architectural design.

In the Islamic world great mosques and palaces usually had vaulted or domed ceilings, which were often decorated with mosaic, painted Koranic inscriptions, or carved stalactite ornament that produced a honeycombed effect [4]. Simpler buildings had flat ceilings of beams and plasters which are flat or concave ceilings with artesonado work-delicate coffering richly painted and gilded. Indian temples were often doomed and decorated with rich stone or stucco carving. In Chinese and Japanese temples the roof beams, supported on elaborately carved painted wooden brackets, were revealed [5].

The acoustics of a building was an undeveloped aspect of the study of sound until comparatively recent times [6]. The Roman architect Marcus Pollio, who lived during the 1st century BC, made some pertinent observations on the subject and some astute guesses concerning reverberations and interference. The scientific aspects of this subject, however, were first thoroughly treated by the American physicist Joseph Henry in 1956 and more fully developed by the American physicist Wallace Sabine in 1900 [1, 21].

An important aspect of room acoustics is insulation from unwanted sound, by using massive walls, by several unconnected walls separated by dead spaces.

This study aims to determine the potential of using pleko for interior finishing for walls and ceilings specifically the properties of the Pleko wall that can be adopted to be used in the ceilings as a new trend in ceiling insulations and identify the advantages of using Pleko as interior finishing for ceilings.

The application of pleko ceiling insulation system may explore the intellectual minds of the researchers to enhance their interest in the fast developing trends of construction particularly in ceiling industry. The experiment conducted may lead to a better understanding of the researchers to study more about the newly developed insulating materials that is widely used in ceilings. This will lead to provide them enough tests results and interpretation to prove that the thermal insulation of Pleko maybe possibly applicable in ceilings to reduce the flow of heat between hot and cold regions.

Moreover, civil designers and engineers will enable to design a structure in which the insulation comes within its ceiling. Through the use of pleko ceiling board, the insulation of rooms and reduce the reflection of sound would be its main purpose. This study would also help them to design a structure that would leave a ceiling with a likenew appearance, environmental friendly and economical.

\section{Related Literature}

Engineering materials are employed to design and build structures, develop new products [7, 15]. Recent developments are focused on producing insulation materials such as Styrofoam, Fiberglass, gypsum, plaster, wood and other insulators that are heat and sound absorbers. It became apparent that new trends of development could only be realized if additional process were developed and that was user friendly and would in fact, leave a ceiling with a like-new appearance.

Ceilings are the upper interior surface of a room. Usually the term refers to a flat or curved surface that conceals the underside of a roof or the floor above, but it may also refer generally to the exposed underside $[8,16]$. 
According to $[9,11]$, insulation is a material or devised used to inhibit or prevent the conduction of heat or electricity. Common heat insulators are fur, feathers, fiberglass, cellulose fibers, stone, wood and wool in which all are poor conductors of heat. The use of asbestos, formerly a common insulating material, has been curtailed due to its implication of lung disease. Industrial furnaces are built of brick, which conduct heat so slowly that a high temperature within is barely apparent in the temperature of the other surface. Steam pipes and water pipes are commonly insulated with thick wrappings of fiberglass pulp [10, 12]. Since insulators prevent the flow of heat in either direction, refrigerators are commonly constructed with double walls separated by an airspace (air being a poor conductor) and lined with some insulating material .The use of double walls or hollow tiles in buildings prevents the entrance of heat and its escape. The very effective insulation in a vacuum bottle results almost entirely from the presence of a vacuum between walls of the inner flask [13].

According to [14, 15], "thermal insulation may have to fulfill one or more of three functions: to reduce thermal conduction in the materials, in which heat is transferred by the electrons; to reduce thermal convection currents, which can be set up in air or liquid filled spaces; and to reduce radiation heat transfer, in which thermal energy is transported by electromagnetic waves". Conduction and convection are suppressed in a vacuum, in which radiation is the only method of transferring heat. If the surfaces are made highly reflective, radiation can also be reduced [16]. Thus, thin aluminum foil can be used in building walls, and reflecting metal on roofs minimizes the heating effect of the sun. Thermos bottles or Dewar flasks retain or exclude heat because they have double walls that have reflective silver or aluminum coatings and are separated by the vacuum.

Air offers about 15,000 times as much as resistance to heat flow as a good thermal conductor such as silver does, and about 30 times as much as a glass. Typical insulating materials, therefore, are usually made of non-metallic materials and are filled with small air pockets. They include magnesium carbonate, cork, felt, cotton batting, rock or glass wool, and diatomaceous earth.

According to $[17,18]$, that wave nature of sound was first measured the speed of sound in air. Boyle in 1660 discovered that sound must travel in a medium. Newton demonstrated the relationship between the speed of sound with the density and compressibility of a medium [20]. Bernoulli (mid-1700s) showed that a string could vibrate at more than one frequency [19].

Architectural acoustics are used to design halls that have the optimum reverberation times and much of the pioneering work was done by the American Wallace Sabine (1868-1919) and the Boston Symphony Concert Hall designed by Sabine is still considered as one of the world's premier concert halls [21, 23]. The musical ambience of a room is determined not only by the walls, floor and ceiling but on the covering of the interior surfaces by fabrics, wood, plaster, acoustic tiles etc., soft surfaces absorb sound and deaden acoustic whereas hard surfaces reflect the sound and liven the acoustic [22, 24].

\section{Conceptual Framework}

As shown in Figure 1, water resistant core gypsum sheathing complying with ASTM C 79, a minimum of $1 / 2$ inch $(12.70 \mathrm{~mm})$ thick, is attached to the steel studs. Steel studs minimum No.20 gage, are spaced a maximum of 16 inches $(406.4 \mathrm{~mm})$ on center, and gypsum sheathing is attached with No.8 gage, 1 inch-long $(25.4 \mathrm{~mm})$, self-drilling drywall screws spaced a maximum of six inches $(152.4 \mathrm{~mm})$ on center. Then the Portland cement (type II or I) with ratio of $1: 1$ by weight is blended with the pleko dry adhesi ve base coat that is mixed with $1 \frac{1 / 2}{2}$ to 2 gallons of water $(5.68 \mathrm{~L}$ water per bag). 
The pleko dry thermal adhesive is applied over the entire face of precut foam insulation board or Styrofoam, using a U-notched trowel .The boards are applied over the gypsum sheathing and pressure is applied over the entire surface to ensure uniform contact and tightly butted joints. The adhesive is allowed to cure for 24 hours before installation of other components.

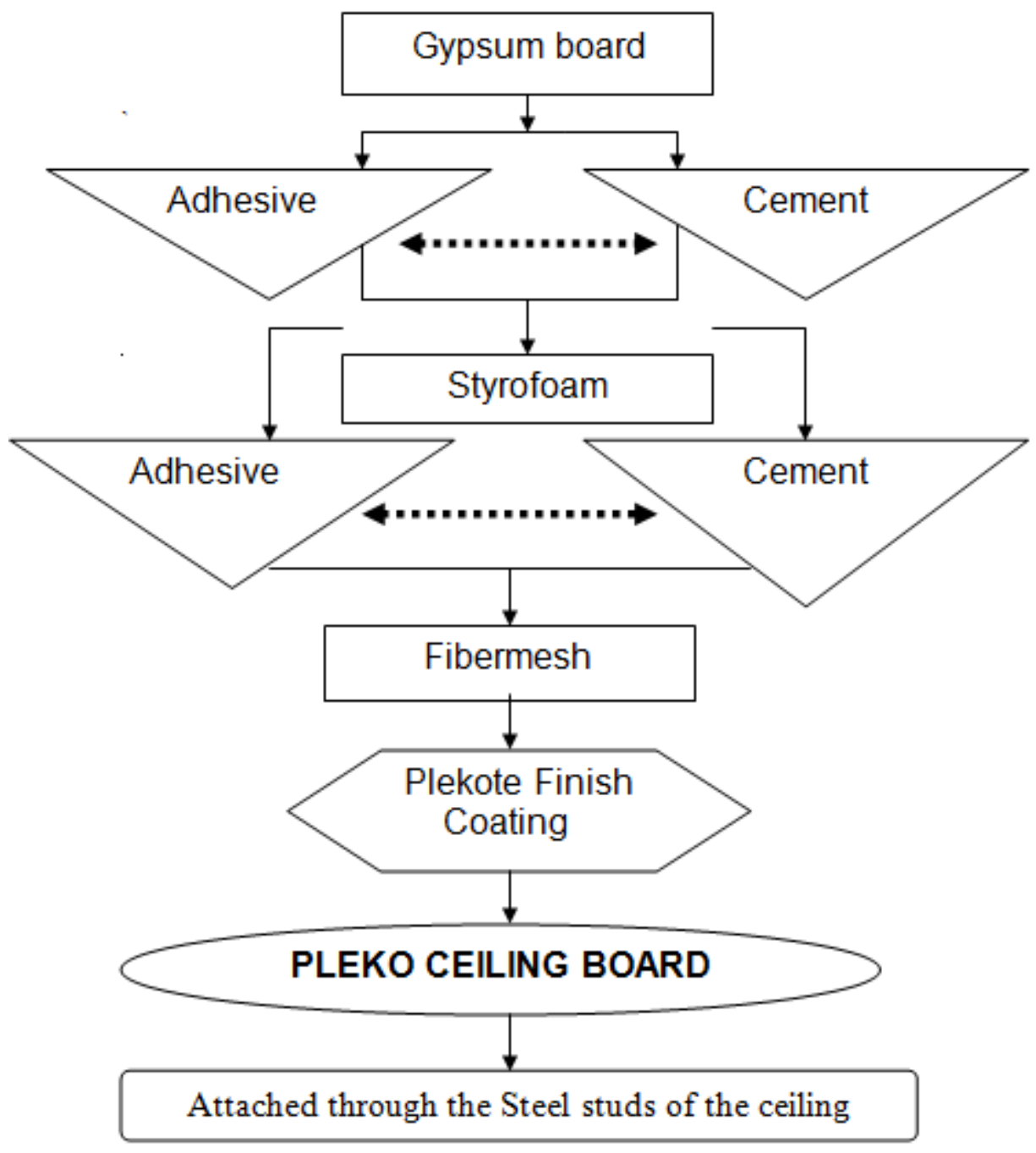

Figure 1. Conceptual framework

After the curing of adhesive, the coating application, the insulation boards are leveled by rasping before application of coating materials. A base coat of pleko noncementations base coat is applied with a stainless steel trowel to the entire board surface to a uniform thickness of approximately $1 / 16$ inch $(1.59 \mathrm{~mm})$. The glass fiber reinforcing fabric is toweled into the wet base coat from center to edges so that no mesh color is visible. The fabric is continuous around corners and is lapped at least 3 inches $(76.20 \mathrm{~mm})$ along edges. Then the pleko finish coat is applied after the base coat has cured a minimum of 24 hours. 
The finish coat is mix with a high-speed mixer until a uniform consistency is obtained. Small amounts of clean, potable water may be added for workability. The materials is applied with a stainless steel trowel is sprayed directly onto the reinforced base coat and leveled in the same operation. The finish coat thickness shall be equal to the diameter of the largest aggregate, approximately $1 / 10$ inch $(1.59 \mathrm{~mm})$.

\section{Experimental Investigation}

\subsection{Methodology}

The experiments made were in a set of ceiling combined of 6 layers containing the foam plastic insulation board, Pleko adhesives, mechanical fasteners, reinforcing fabric, plekote base coat and pleko finish. These components are being attached on the interior face. Also, the existing projects for the EIFS are made to provide for the sound insulation comparison.

\subsection{Materials}

Five components of materials are used in this experiment. Namely, Styrofoam brand insulation, having an average density of $2.0 \mathrm{pcf}$, mechanical fasteners no.10, corrosiontreated Philips bugle head, self-tapping steel screws. The steel screws into Pleko fastener disk, which is a minimum $13 / 4$ inch-diameter reinforcing fabric, made from twisted multi-end strands that are treated for compatibility with other pleko materials when protected from moisture, the plekote reinforcing has an indefinite shelf life. Plekote base coat is a fiber-reinforced, ready mixed, acrylic copolymer admixture having a shelf life of five years when stored in ambient temperatures between $40^{\circ} \mathrm{F}$ and $125^{\circ} \mathrm{F}\left(4.4^{\circ} \mathrm{C}\right.$ and $\left.51.7^{\circ} \mathrm{C}\right)$. Pleko finish coat is 100 percent acrylic polymer based wall coating made with silica and / or marble aggregates.

\subsection{Experimental Procedure}

Water resistant, core-treated pleko heating, complying with ASTM C 79, a minimum of $1 / 2$ inch $(12.70 \mathrm{~mm})$ thick, is attached to steel or wood studs shown in Figure 2. Wood studs are spaced a maximum of 16 inches $(406.4 \mathrm{~mm})$ on center, and pleko sheathing is attached in accordance with the applicable code. Steel studs, minimum No. 20 gage, are spaced a maximum of 16 inches $(406.4 \mathrm{~mm})$ on center, and pleko sheathing is attached with No. 8 gage, 1-inch long $(25.4 \mathrm{~mm})$, self-drilling drywall screws spaced a maximum of 6 inches $(152.4 \mathrm{~mm})$ on center, or is installed in accordance with the gypsum manufacturer's specifications. The Pleko thermal adhesive or the dry thermal adhesive is applied over the entire face or precut foam insulation boards, using a $3 / 8$ inch $(9.53 \mathrm{~mm})$ square notched trowel. When the perm fast adhesive is used, the adhesive is spread over the entire back surface of the insulation boards, using a Unotched trowel having notches that are $3 / 16$ inch $(4.76 \mathrm{~mm})$ deep by $3 / 16$ inch $(4.76$ $\mathrm{mm}$ ) wide, with the notches spaced $1 \frac{1 / 2}{2}$ inches $(38.10 \mathrm{~m})$ on center. The boards are applied over the pleko sheathing and pressure is applied over the entire surface to ensure uniform contact and tightly butted joints. The adhesive is allowed to cure for 24 hours before the installation of other components.

The insulation boards are leveled by rasping before application of coating materials. A base coat of either pleko non-cementations or cementations base coat, WP base coat, thick base coat or dry adhesive/base coat is applied with a stainless steel trowel to the entire board surface to a uniform thickness of approximately $1 / 16$ inch $(1.59 \mathrm{~mm})$. The glass fiber reinforcing fabric is troweled into the wet base coat from center to edges so 
that no mesh color is visible. The fabric is continuous around corners and is lapped at least 3 inches $(76.20 \mathrm{~mm})$ along edges. The fabric is wrapped around insulation board terminations with a 3 -inch $(76.20 \mathrm{~mm})$ return.

The pleko finish coat is applied after the base coat has cured a minimum of 24 hours. The finish coat is mixed with a high-speed mixer until a uniform consistency is obtained. Small amounts of clean, potable water may be added for workability. The material is applied with a stainless steel trowel or is sprayed directly onto the reinforced base coat and leveled in the same operation. The finish coat thickness shall be at least equal to the diameter of the largest aggregate, approximately $1 / 16$ inch $(1.59 \mathrm{~mm})$.

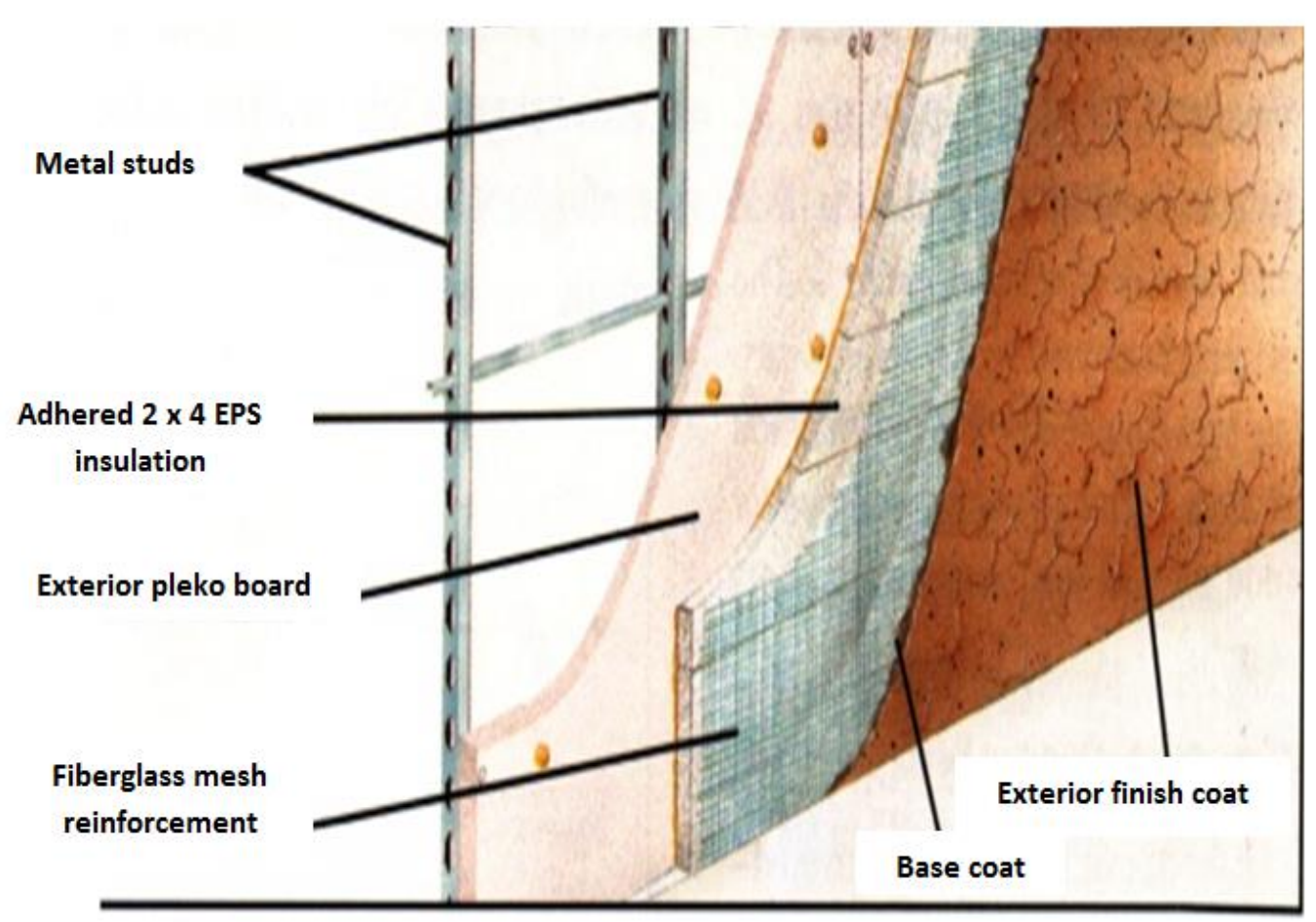

Figure 2. Schematic diagram of installing pleko

\subsection{Design criteria}

The purpose of thermal insulation in buildings is to maintain a comfortable and hygienic indoor climate at low ambient temperatures. A minimal amount of thermal insulation is required to protect the constructional elements against thermal impact and moisture related damage. The main aim of thermal insulation in winter is energy conservation leading to a decrease in heating demand and hence the protection of the environment. This aim has to be considered in new buildings as well as in renovating the building stock. Strategies to reach this aim are the use of building materials with low and the installation of windows with low U-values. Moreover, thermal insulation plays a major role in preventing summertime overheating of buildings through reducing the transmission of solar radiation, absorbed on the building's exterior surfaces, to the interior. The lowest $\lambda$-values of nonevacuated elements achievable is the one of motionless air. Hence the basic principle in developing insulation materials is to enclose as much non-moving air into the structure of the material as possible and still satisfy the structural stability required. The lowest 
achievable $\lambda$-values of insulation elements are realized with evacuated insulation panels. Parameters related to building Physics.

The thermal properties of structural elements are characterized by the mass density, $\rho$ the $\lambda$-values of the building elements layers and the heat transfer coefficients $\alpha$ at the surfaces. The heat transmission through an element is defined by the air to air heat transmission coefficient $\mathrm{U}$.

Reducing the $\lambda$-value of a material or increasing the thickness of the insulation layer results in a decreasing $U$-value. The heat transfer coefficients are composed of a convective and a radioactive part. The heat transfer mechanisms are shown in Figure 3.

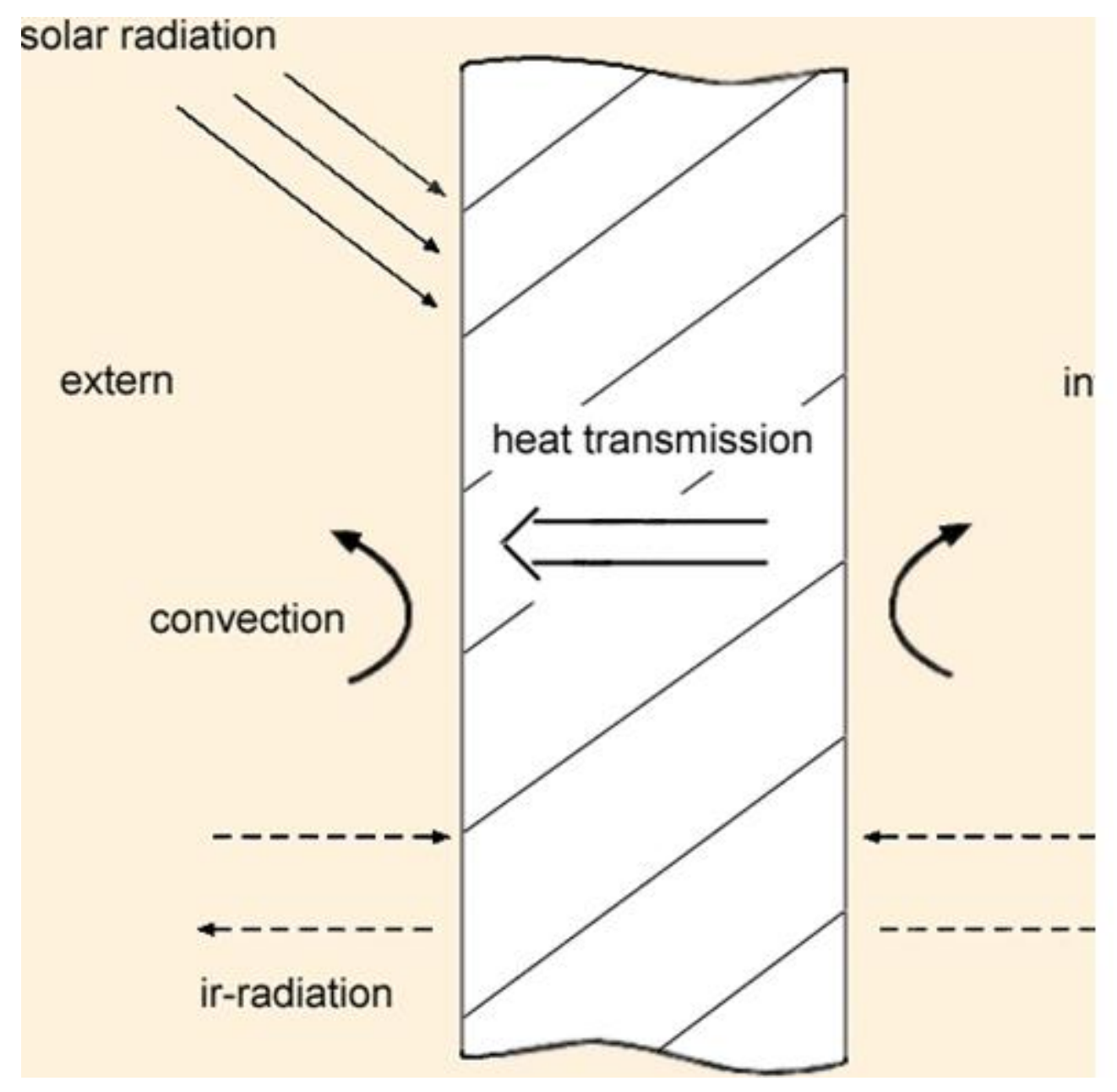

Figure 3. Thermal transfer mechanisms of an exterior partition in the heating season

\section{Results and Discussion}

\subsection{Thermal insulation test}

Each board is composed of a non-combustible pleko board core with paper laminated surfaces which provide tensile strength to the lining. Pleko contains chemically bound water and a small amount of free water, which play a key role in the performance of the assembly at elevated temperatures. During a fire, when pleko board is heated up to 
about $100^{\circ} \mathrm{C}$, a great amount of heat is absorbed to drive off water. This process therefore delays the development of temperature rise through pleko until the entire board is dehydrated. The consequent temperature plateau is the basis of pleko board systems fire resistance as shown in Figure 4.

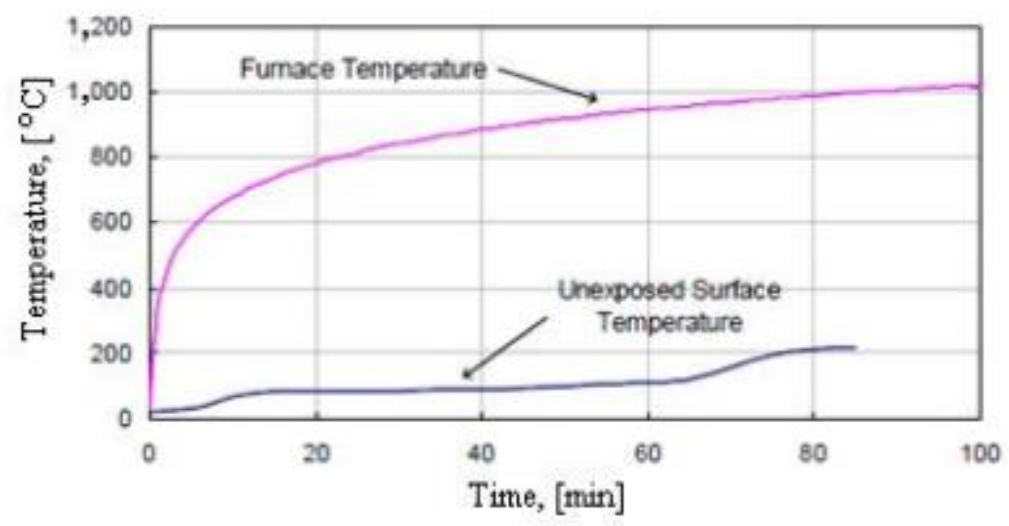

Figure 4. Temperature development on the unexposed side of a pleko board

\subsection{Sound insulation test}

Considering the Sound Transmission Class (STC), Table 1 presents results of STC for different wall configurations in measurements. The results show that a brick wall, $12.5 \mathrm{~cm}$ thick, has a STC of $43 \mathrm{~dB}$ and a single layer gypsum board with $10 \mathrm{~cm}$ glass wool has STC of $51 \mathrm{~dB}$. Even being thinner than regular walls, pleko board may achieve better STC results when corrected designed. However, this arrangement is still below the STC 47, where loud conversation can be weakly audible.

Table 1. Acoustical properties of usual wall arrangement

\begin{tabular}{|l|c|c|}
\hline \multicolumn{1}{|c|}{ Configuration } & $\begin{array}{c}\text { Thickness } \\
\text { (cm) }\end{array}$ & STC \\
\hline Porous cement block with plasterboard on both sides & 10 & 34 \\
\hline Single layer pleko board on steel studs, empty internal space & 7.3 & 37 \\
\hline Ceramic hollow block with plasterboard on both sides & 10 & 43 \\
\hline $\begin{array}{l}\text { Single layer pleko board on steel studs, internal space with mineral } \\
\text { wool of 16 kg/m }\end{array}$ & 14 & 51 \\
\hline $\begin{array}{l}\text { Double layer pleko board on steel studs, internal space with mineral } \\
\text { wool of } 16 \mathrm{~kg} / \mathrm{m}^{3}\end{array}$ & 14 & 62 \\
\hline
\end{tabular}

A relevant issue for the sound insulation performance of the pleko partitions is the interface between walls and doors. There are two ways to fix doors structures in dry walls. Firstly, small bits of wood are inserted into the steel stud and screws are used to fix the door to the wood pieces. A lot of air space is left around the boundary and will be only hidden by a wooden finishing. An alternative means to fix doors is using flexible polyurethane expansible foam. In this way, foam is injected in six points around the door edges. This is enough to keep the door in place, but it also leaves many cavities connecting each side of the wall. 
In an ordinary brick wall, this problem would not exist because it is common practice to use plasterboard to fix the door and seal the opened spaces. Regarding the sealing around each pleko panel, there is no standard for tapes, setting compounds and plasters. Inflexible plasters have been used and result in crack appearing along the height of the panels, which let the sound go through.

\section{Conclusion}

It is concluded that pleko board may have adequate performance when specifications are correct done. Besides it gives the possibility that the properties of pleko board could be adopted to be used in ceilings. One of its properties is the ability to reduce thermal heat between hot and cold regions of a structure. Moreover, pleko ceiling board is easy to install, durable and energy efficient. A minimal amount of thermal insulation protects the constructional elements against thermal impact and moisture related damage

The acoustic properties of pleko board play an important role to reduce heat for the insulation inside the building. This serves as a sound proofing material of pleko board that is installed on the walls and ceilings for any type of building. For sound insulation, the results prove that it could give the best insulation of sound as long as the wall was also installed with pleko.

Finally, the quality of the workmanship is decisive to get in situ performance similar to the laboratory. Execution and fixing can take from an appropriated design to an inappropriate condition.

\section{References}

[1] M. Madan, "Architectural Acoustics: Principles and Design”, National Bookstore, Manila, (1999).

[2] T. U. Ganiron Jr, "Use of Recycled Glass Bottles as Fine Aggregates in Concrete Mixture", International Journal of Advanced Science and Technology, vol. 61, (2013) December, pp.17-28.

[3] C. Hopkins, "Sound Insulation", National Bookstore, Manila, (2012).

[4] V. Hongisto, "Sound Insulation of Doors-Part 1: Prediction Models for Structural and Leak Transmission", Journal of Sound and Vibration, vol. 230, no. 1, (2000), pp. 133-148.

[5] T. U. Ganiron Jr, "Effects of Rice Hush as Substitute for Fine Aggregate in Concrete Mixture", International Journal of Advanced Science and Technology, vol. 58, (2013) September, pp. 29-40.

[6] B. Rasmussen, "Sound Insulation between Dwellings: Classification Schemes and Building Regulations in Europe", Inter-Noise and Noise-CON Congress and Conference Proceedings, vol. 3, (2004).

[7] T. U. Ganiron Jr, "Analysis of Fly Ash Cement Concrete for Road Construction", International Journal of Advanced Science and Technology, vol. 60, (2013) November, pp. 33-34.

[8] T. U. Ganiron Jr, "Concrete Debris a Fine Aggregate for Architectural Finishing Mortar", Architectural Journal, vol. 2, no. 5, (2012) December.

[9] C. Grimwood, "Complaints about Poor Sound Insulation between Dwellings in England and Wales", Applied Acoustics, vol. 52, no. 3, (1997), pp. 211-223.

[10] T. U. Ganiron Jr, "Investigation on the use of Coco Coir Polypropylene as Thermal Insulator", International Journal of Advanced Science and Technology, vol. 59, (2013) October, pp. 13-26.

[11] H. Vogg and L. Stieglitz, "Thermal Behavior of PCDD/PCDF in Fly Ash from Municipal Incinerators", Chemosphere, vol. 15, no. 9, (1986), pp. 1373-1378.

[12] T. U. Ganiron Jr, "Forensic Investigation of Abandoned GSIS Building in Manila", International Journal of Disaster Recovery and Business Continuity, vol. 4, (2013) November, pp. 23-34.

[13] W. Scholl and W. Maysenholder, "Impact Sound Insulation of Timber Floors: Interaction between Source, Floor Coverings and Load Bearing Floor", Building Acoustics, vol. 6, no. 1, (1999), pp. 43-6.

[14] T. U. Ganiron Jr, "Effect of Thermoplastic as Fine Aggregate to Concrete Mixture", International Journal of Advanced Science and Technology, vol. 62, (2014) January.

[15] T. U. Ganiron Jr, "Testing Water Vapour Permeability of Sawdust and Banana Peels Ply Board as NonVeneer Panel”, International Journal of Construction Engineering and Management, vol. 2, no. 2, (2013) March.

[16] T. U. Ganiron Jr, “An Investigation of Moisture Performance of Sawdust and Banana Peels Ply board as Non- 
Veneer Panel", International Journal of u- and e- Service, Science and Technology, vol. 6, no.3, (2013) June, pp. 43-54.

[17] Al-Homoud and S. Mohammad, "Performance Characteristics and Practical Applications of Common Building Thermal Insulation Materials" Building and Environment, vol. 40, no. 3, (2005), pp. 353-366.

[18] T. U. Ganiron Jr, "Effect of Sawdust as Fine Aggregate in Concrete Mixture for Building Construction", International Journal of Advanced Science and Technology, vol. 63, (2014) February.

[19] T. Mahlia, N. Taufiq and H. H. Masjuki, "Correlation between Thermal Conductivity and Thickness of Selected Insulation Materials for Building Wall”, Energy and Buildings, vol. 39, no. 2, (2007), pp. 182-187.

[20] T. U. Ganiron Jr, "Pelletized Cut Rubber: An Alternative Coarse Aggregate for Concrete Mixture", International Journal of Advanced Science and Technology, vol. 64, (2014) March.

[21] Al-Jabri, S. Khalifa, "Concrete Blocks for Thermal Insulation in Hot Climate", Cement and Concrete Research, vol. 35, no. 8, (2005), pp. 1472-1479.

[22] T. U. Ganiron Jr, "Influence of Polymer Fiber on Strength of Concrete", International Journal of Advanced Science and Technology, vol. 55, (2013) June, pp. 53-66.

[22] B. Hanifi, "Thermal Isolation and Mechanical Properties of Fibre Reinforced Mud Bricks as Wall Materials", Construction and Building Materials, vol. 21, no. 4, (2007), pp. 901-906.

[23] T. U. Ganiron Jr, "Recycling of Waste Coconut Shells as Substitute for Aggregates in Mix Proportioning of Concrete Hollow Blocks", WSEAS Transactions on Environment and Development, vol. 9, no. 4, (2013) October, pp. 27-38.

[24] T. U. Ganiron Jr, "Utilization and End-Users Acceptability of Compressed Lahar Sediment Blocks as Wall Panel for Low Cost Housing”, WSEAS Transactions on Environment and Development, vol. 9, no. 3, (2013) July, pp. 206-219.

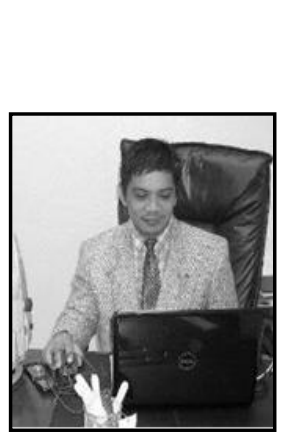

\section{Author}

\section{Tomas Ucol Ganiron Jr.}

This author obtained his Doctor of Philosophy in Construction Management at Adamson University (Philippines) in 2006, and subsequently earned his Master of Civil Engineering major in Highway and Transportation Engineering at Dela Salle University-Manila (Philippines) in 1997 and received Bachelor of Science in Civil Engineering major in Structural Engineering at University of the East (Philippines) in 1990. He is a registered Civil Engineer in the Philippines and Professional Engineer in New Zealand. His main areas of research interest are construction engineering, construction management, project management and recycled waste materials. He has been the resource person in various seminars in New Zealand (like in Auckland University of Technology, University of Auckland and University of Canterbury). He was connected with Advanced Pipeline System in New Zealand as Construction Manager wherein he supervised the sewerage and waterworks projects. He was the former Department Head of Civil Engineering in FEATI University (Manila) and former Department Head of Physics in Emilio Aguinaldo College (Manila). He is also very active in other professional groups like Railway Technical Society of Australasia and Australian Institute of Geoscientists where he became committee of Scientific Research. He has received the Outstanding Civil Engineer in the field of Education given by the Philippine Media Association Inc. (1996), ASTM Award CA Hogentogler (2008) by IPENZ in New Zealand and Outstanding Researcher (2013) in Qassim University, Buraidah City. 